\title{
Targeting Bruton Tyrosine Kinase: A novel strategy in the treatment of B-cell lymphomas
}

\author{
Sklavenitis-Pistofidis R. ${ }^{1}$, Koletsa T. ${ }^{2}$, Lazaridou A. ${ }^{1}$, Goulas A. ${ }^{* 1}$ \\ ${ }^{1} 1$ st Laboratory of Pharmacology, Faculty of Medicine, \\ Aristotle University of Thessaloniki, 54124 Thessaloniki, Greece
}

${ }^{2}$ Department of Pathology, Faculty of Medicine,

Aristotle University of Thessaloniki, 54124 Thessaloniki, Greece

Received 8 September 2016; Accepted 24 August 2017

\begin{abstract}
In normal B-cells, Bruton tyrosine kinase (Btk), a non-receptor tyrosine kinase involved in B-cell receptor (BCR) signalling, is essential for cell survival and maturation. Not surprisingly, Btk is also implicated in the pathogenesis of B-cell lymphomas, like Chronic Lymphocytic Leukaemia/Small Lymphocytic Lymphoma (CLL/SLL), Mantle Cell Lymphoma (MCL) and Waldenström's Macroglobulinemia (WM), which are driven by aberrant BCR signalling. Thus, targeting Btk represents a promising therapeutic strategy in the treatment of B-cell lymphoma patients. Ibrutinib, a selective Btk inhibitor, has already been approved as second-line treatment of CLL/SLL, MCL and WM patients, while more clinical studies of ibrutinib and novel Btk inhibitors are currently under way. In light of results of the RESONATE-2 trial, the approval of ibrutinib as a first-line treatment of CLL/SLL may well be approaching. Herein, we review Btk's role in normal and malignant BCR signalling, as well as ibrutinib's performance in B-cell lymphoma treatment and prognosis.
\end{abstract}

Keywords: Bruton • tyrosine $\bullet$ kinase $\bullet$ inhibitor $・$ ibrutinib $\bullet B C R \bullet$ lymphoma $\bullet C L L ・$ treatment

(C) De Gruyter Open

\section{List of Abbreviations (alphabetically)}

ABC DLBCL: Activated B-cell Diffuse Large B-cell Lymphoma

BCR: B-cell Receptor

BLNK: B-cell Linker Protein

Btk: Bruton Tyrosine Kinase

CLL/SLL: Chronic Lymphocytic Leukaemia/Small Lymphocytic Lymphoma

CR: Complete Response

DAG: Diacylglycerol

DLBCL: Diffuse Large B-cell Lymphoma

FL: Follicular Lymphoma

HL: Hodgkin lymphoma

IGHV: Ig Heavy Variable Gene

$\mathrm{IP}_{3}$ : Inositol Triphosphate

ITAM: Immunoreceptor Tyrosine-based Activation Motif

M-CLL: Mutated Chronic Lymphocytic Leukaemia

MCL: Mantle Cell Lymphoma

mlg: Membrane Immunoglobulin

MYD-88: Myeloid Differentiation 88 Signalling Adaptor

MZL: Marginal Zone Lymphoma

NF-kB: Nuclear Factor Kappa B

NHL: Non-Hodgkin Lymphoma

OS: Overall Survival

PFS: Progression-Free Survival

PI3K: Phosphoinositide 3-Kinase

$\mathrm{PIP}_{2}$ : Phosphatidylinositol 4,5-Biphosphate

$\mathrm{PIP}_{3}$ : Phosphatidylinositol 3,4,5-Triphosphate

PIP5K: Phosphatidylinositol 5-Phosphate Kinase

PKC: Protein Kinase C

PLCy2: Phospholipase C y-2

PTK: Protein Tyrosine Kinase

U-CLL: Unmutated Chronic Lymphocytic Leukaemia

WM: Waldenström's Macroglobulinemia

Xid: X-linked Immunodeficiency

XLA: X-linked Agammaglobulinemia

\section{Introduction}

$B$ cell receptor (BCR) signalling is necessary not only for effective antigen-specific humoral immunity, but also for B-cell maturation and survival. In 1993, it was discovered that mutations in a protein tyrosine kinase (PTK) involved in BCR signalling were the cause of primary 
immunodeficiencies in both men $(1,2)$ and mice $(3,4)$; X-linked Agammaglobulinemia (XLA) in men and X-linked Immunodeficiency (Xid) in mice are both characterized by a block in B-cell development at the pro-B cell stage, lack of mature B-cells, antibody deficiency and recurrent bacterial infections. ${ }^{[5]}$ The kinase involved was named Bruton tyrosine kinase (Btk) after Dr. Ogden Bruton who first described XLA. The discovery that impaired PTK function could compromise $B$-cell maturation and survival hinted at the importance of BCR signalling in B-cell fate decisions and prompted the evaluation of the role of other signalling components in B-cell activation. Various knockout mice, including knockouts of Phosphoinositide 3-Kinase (PI3K), B-cell Linker (BLNK), Protein Kinase $\mathrm{C}$ (PKC) and Phospholipase C Y-2 (PLCY2), all of them components of the B-cell receptor signalling machinery, exhibited Xid-like phenotype. ${ }^{[6]}$ This led to the realization that they all must be part of a common signalling pathway; that there must be a B-cell 'signalosome' at work, a molecular scaffold responsible for transducing the signal, which would fall apart for the lack of a single component. So far, Btk is the only one of those signalling components whose inherited absence causes disease in humans, and is increasingly recognized as a major mediator of B-cell malignancy pathogenesis.

\section{Btk in normal BCR signalling}

Btk is a member of the Tec family of non-receptor tyrosine kinases, predominantly expressed in B-lymphocytes and cells of the myeloid lineage, but not in plasma cells or T-lymphocytes. ${ }^{[7]}$ Nevertheless, B-cells are the ones that are primarily affected in patients with loss-of-function Btk mutations; thus, for the sake of simplicity, Btk can be considered a B-cell-specific molecule. It contains the following domains, each of which can interact with other proteins for signalling purposes: $\mathrm{PH}, \mathrm{TH}, \mathrm{SH} 2, \mathrm{SH} 3$ and $\mathrm{SH} 1$ (kinase domain). ${ }^{[8]} \mathrm{PH}$ is a pleckstrin homology domain used for binding to Phosphatidylinositol 3,4,5triphosphate $\left(\mathrm{PIP}_{3}\right), \mathrm{TH}$ is a Tec-homology domain that contains a zinc-finger motif, $\mathrm{SH} 2$ is an Src homology domain that allows docking to phosphorylated tyrosine residues on other proteins and $\mathrm{SH} 3$ is an Src homology domain used for protein-protein interactions that contains an activating site of autophosphorylation (Figure 1).

$\mathrm{PH}$ : Pleckstrin homology domain. TH: Tec homology domain. SH2, SH3: Src homology domains. SH1/TK: tyrosine kinase domain. $\mathrm{PIP}_{3}$ : Phosphatidylinositol 3,4,5-triphosphate. PKC: Protein kinase C. Lyn, Syk: Src-family tyrosine kinases. BLNK: B-cell linker protein. PLCy2: Phospholipase C $\mathrm{\gamma}-2$. NF-kB: Nuclear factor kappa B.

Btk contains five domains through which it interacts with other proteins of the B-cell receptor signalling pathway, leading to PLCY2 and eventually, NF-kB activation. $\mathrm{PH}$ is used for binding to $\mathrm{PIP}_{3}$, which recruits Btk to the plasma membrane; $\mathrm{TH}$ contains a zinc-finger motif; $\mathrm{SH} 2$ is used for docking to phosphorylated tyrosine residues on other proteins, allowing for interaction with proteins, such as BLNK and Lyn/Syk tyrosine kinases; $\mathrm{SH} 3$ contains a site of autophosphorylation, necessary for Btk activation; $\mathrm{SH} 1$ is a tyrosine kinase domain, used for PLCy2 activation.

The B-cell receptor consists of a membrane immunoglobulin (m/g) produced through $\mathrm{V}(\mathrm{D}) \mathrm{J}$ recombination, associated with two other proteins, Ig- $\alpha$ (CD79a) and Ig- $\beta$ (CD79b), which contain immunoreceptor tyrosine-based activation motif (ITAM) regions in their cytoplasmic terminal domains. ${ }^{[9]} \mathrm{BCR}$ signalling is outlined graphically in Figure 2. The pathway is initiated by antigen-binding to $\mathrm{mlg}$, although

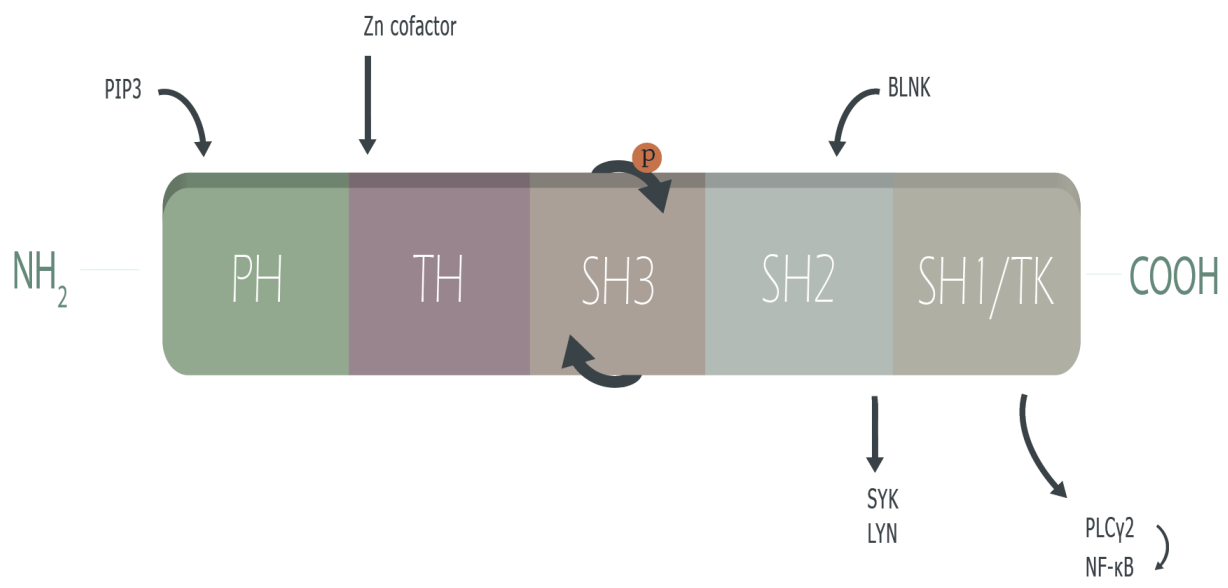

Figure 1. Bruton tyrosine kinase (Btk) molecular structure. 


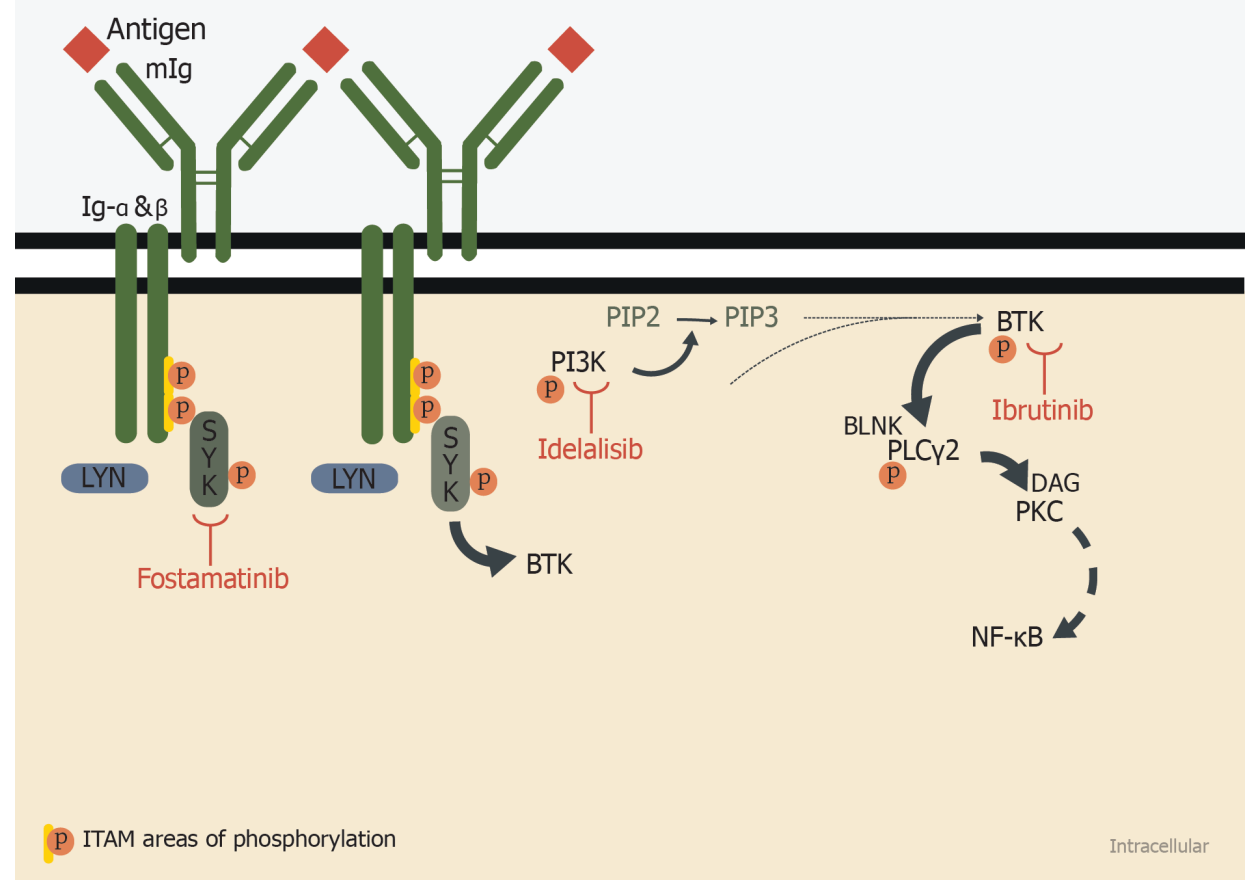

Figure 2. B-cell Receptor (BCR) signalling pathway.

a basal antigen-independent signal is also generated to allow for cell development and survival. ${ }^{[10]}$ Following antigen-binding, the ITAM regions of Ig- $\alpha$ and $\lg -\beta$ are phosphorylated by the Src family kinases Lyn, Fyn and Blk. ${ }^{[11]}$ Those kinases also increase the activity of the Syk kinase, ${ }^{[12]}$ which - via its own $\mathrm{SH} 2$ domain - binds to phosphorylated Ig- $\alpha$ and $\lg -\beta .{ }^{[13]}$ As a result of BCR ligation, $\mathrm{PI} 3 \mathrm{~K}$ is also activated; it then phosphorylates phosphatidylinositol 4,5-biphosphate $\left(\mathrm{PIP}_{2}\right)$, producing phosphatidylinositol 3,4,5-triphosphate $\left(\mathrm{PIP}_{3}\right)$, which in turn recruits cytoplasmic Btk to the plasma membrane through binding to its $\mathrm{PH}$ domain. ${ }^{[14]}$ Once there, Btk is phosphorylated by Lyn and Syk at tyrosine residue $551^{[15]}$ and then autophosphorylated at tyrosine residue 223 within its own SH3 domain, ${ }^{[16]}$ rendering itself active. Subsequently, Btk interacts with adaptor protein BLNK through its $\mathrm{SH} 2$ domain and the two together activate PLCY2. ${ }^{[17]}$ PLCy2 utilizing PIP $_{2}$ - the same substrate as $\mathrm{PI} 3 \mathrm{~K}$ - produces Inositol Triphosphate $\left(\mathrm{IP}_{3}\right)$ and Diacylglycerol (DAG), which in turn mobilize intracellular calcium and activate PKC, respectively. ${ }^{[5,18]}$ These intracellular changes culminate in the activation of Nuclear Factor kappa-B (NF-KB $)^{[19]}$ and other transcription factors, which then regulate the expression of genes related to B-cell survival, development and proliferation, such as $\mathrm{Bcl}-\mathrm{X}_{\mathrm{L}} \cdot{ }^{[5]}$ Of note, Btk upregulates phosphatidylinositol 5-phosphate kinase (PIP5K), the enzyme responsible for producing $\mathrm{PIP}_{2}$, which is a substrate for both PI3K and PLCY2, thus enhancing their activity, ${ }^{[20]}$ while it also plays a role in B-cell migration and adhesion. ${ }^{[21,22]}$

Lyn, Syk: Src-family tyrosine kinases. PI3K: Phosphoinositide 3-kinase. $\mathrm{PIP}_{2}$ : Phosphatidylinositol 4,5-biphosphate. $\mathrm{PIP}_{3}$ : Phosphatidylinositol 3,4,5triphosphate. BLNK: B-cell linker protein. PLCY2: Phospholipase C Y-2. DAG: Diacylglycerol. PKC: Protein kinase C. NF-kB: Nuclear factor kappa B.

BCR consists of a membrane immunoglobulin (mlg), noncovalently associated with Ig- $\alpha$ (CD79a) and lg- $\beta$ (CD79b), which contain immunoreceptor tyrosine- 
based activation motif (ITAM) regions. Following antigen-binding, the ITAM regions of $\lg -\alpha$ and $\lg -\beta$ are phosphorylated by Lyn, an Src-family kinase. Syk, another Src-family kinase, then binds to phosphorylated Ig- $\alpha$ and Ig- $\beta$; while PI3K, another kinase activated through $\mathrm{BCR}$ ligation, phosphorylates $\mathrm{PIP}_{2}$, producing $\mathrm{PIP}_{3}$ in turn recruits cytoplasmic Btk to the plasma membrane. Once there, Btk is phosphorylated by Lyn and Syk and then autophosphorylated, rendering itself active. Btk then interacts with BLNK and, together, they activate PLCy2. PLCy2 produces DAG, which in turn activates $\mathrm{PKC}$. These intracellular changes culminate in the activation of NF-KB and other transcription factors, which then regulate the expression of genes related to B-cell survival, development and proliferation.

\section{Btk in B-cell malignancies (CLL, MCL, DLBCL, WM, FL, MZL, HL)}

Aberrant BCR signalling has been linked to a number of B-cell malignancies, but most commonly Chronic Lymphocytic Leukaemia (CLL), where it is now considered a major promoting factor.

Chronic Lymphocytic Leukaemia is strongly dependent on microenvironmental cross-talk. CLL cells undergo apoptosis when cultured in vitro, unless they are co-cultured with nurse-like cells or stromal cells (i.e., cells from the leukemic microenvironment), which are apparently required for leukemic cell survival. ${ }^{[23]}$ In fact, there are multiple cellular (stromal cells, T-cells, nurse-like cells) and molecular (CXCR4, CXCR5, etc.) interactions at play, ${ }^{[24]}$ but BCR signalling and antigen stimulation in particular lie at the centre of disease pathogenesis.

In 1998, it was discovered that CLL B-cells express a restricted Ig heavy variable (IGHV) gene repertoire. [25] More specifically, CLL B-cells are biased towards the use of certain $\mathrm{V}_{\mathrm{H}}$ genes, that preferentially combine with certain $\mathrm{D}$ or $\mathrm{J}_{\mathrm{H}}$ segments, creating similar antigenbinding pockets. ${ }^{[26]}$ Furthermore, the BCRs of CLL cells from various patients exhibit similar somatic hypermutation patterns in their IGHV genes, typical of antigen receptors that have undergone selection by antigen. ${ }^{[27]}$ Thus, it appears that the BCRs of CLL cells from different patients are often structurally similar or 'stereotyped', exhibiting little variation among different subsets of patients, despite the very many possible VDJ combinations. ${ }^{[28-31]}$ This phenomenon is diseaserestricted, ${ }^{[32,33]}$ as it differs from the wider diversity of BCRs found in normal B-cells, and it suggests a limited set of (auto)antigens stimulating clonal evolution in CLL pathogenesis. ${ }^{[34,35,36]}$
B-cell receptor signalling in CLL is heterogeneous, depends on the levels of surface IgM (37) and correlates with tumour behaviour. ${ }^{[38]}$ Generally, the two subtypes of CLL are recognized, mutated CLL (M-CLL) and unmutated CLL (U-CLL), depending on whether the B-cell mlg has undergone somatic hypermutation or not. In M-CLL, following somatic hypermutation, the surface $\lg \mathrm{M}$ either exhibits avid affinity to antigen or no affinity at all; either way, the surface IgM is eventually downregulated and the $\mathrm{B}$-cell is rendered anergic over time. [38] On the contrary, in U-CLL, the surface IgM that has not undergone hypermutation retains its polyreactivity and, upon ligation to various (auto)antigens, propagates B-cell clone expansion. ${ }^{[38]}$ Hence, BCR signalling is most important in U-CLL, ${ }^{[39]}$ which is related to more aggressive disease and has a significantly worse prognosis. Apparently, BCR signalling is not only implicated in CLL pathogenesis, but it is also related to the outcome.

There are multiple B-cell malignancies, though, Btk might be involved in the pathogenesis of these malignancies. For example, a distinct Ig heavy variable gene repertoire with somatic hypermutation (again, indicative of antigenic selection) ${ }^{[40]}$ and constitutively active $\mathrm{BCR}$ downstream signalling ${ }^{[41]}$ were discovered in Mantle Cell Lymphoma (MCL) B-cells, indicating a role for $\mathrm{BCR}$ signalling in $\mathrm{MCL}$ pathogenesis as well. What is more, chronic BCR activation is required for cell survival in Activated B-cell Diffuse Large B-cell Lymphoma (ABC DLBCL), ${ }^{[42]}$, making Btk a promising therapeutic target in that subset of DLBCL patients, while the effectiveness of Btk targeting in relapsed/refractory follicular lymphoma (FL) and marginal-zone lymphoma (MZL) suggests a role for Btk there, too. ${ }^{[43]}$ Another example is Waldenström's Macroglobulinemia (WM); Btk is necessary for lymphoplasmacytic cell survival, as it is a downstream target of the Myeloid Differentiation 88 signalling adaptor (MYD88), which carries the most prevalent somatic mutation in WM patients, L265P.

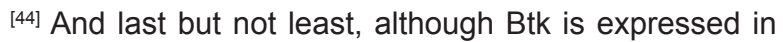
only $20 \%$ of patients with Hodgkin Lymphoma $(\mathrm{HL}),{ }^{[45]}$ targeting it has been shown effective in refractory classic HL. ${ }^{[46]}$

\section{Targeting Btk in B-cell malignancies}

Since aberrant BCR signalling is implicated in the pathogenesis of B-cell malignancies, such as CLL, MCL, ABC DLBCL, FL, MZL, WM and HL, it was only reasonable to evaluate the efficacy of protein kinase inhibitors in their treatment. Thus, a number of PTK inhibitors, such as PI3K and SYK inhibitors, were 
developed and are being tested. Idelalisib, an oral PI3K inhibitor, has progressed into phase III trials in patients with advanced Non-Hodgkin's Lymphoma (NHL), CLL and $M C L,{ }^{[47]}$ while fostamatinib, an oral SYK inhibitor, has induced partial responses in relapsed CLL patients in a phase I/II study. ${ }^{[48]}$ Recently, ibrutinib (PCI-32765), a selective Btk inhibitor, was approved for use in CLL, MCL and WM.

In preclinical studies, ibrutinib was shown to actively inhibit Btk in CLL cells, abrogating BCR-induced survival signals and hindering B-cell migration and homing. ${ }^{[49,50,51]}$ A phase 1 study of ibrutinib in patients with relapsed or refractory B-cell malignancies followed. And for a price of only mild/moderate toxicity, ibrutinib showed potent clinical antitumor activity, with objective responses in $60 \%$ of patients, complete response (CR) in $16 \%$ and a median progression-free survival (PFS) of 13.6 months. ${ }^{[43]}$ Subsequently, a phase $1 \mathrm{~b}-2$ study of ibrutinib in relapsed CLL patients registered an overall response rate of $71 \%$ with $83 \%$ overall survival (OS); the responses were sustained and only varied according to IGHV mutation status $(77 \%$ response in U-CLL and 33\% in M-CLL). ${ }^{[52]}$ Another phase $1 \mathrm{~b}-2$ study in elderly treatment-naive patients with CLL confirmed the mild/moderate toxicity profile and showed a $71 \%$ objective response rate. ${ }^{[53]}$ The phase 3 RESONATE trial of ibrutinib versus ofatumumab (anti-CD20 mAb), for previously treated CLL patients, favoured ibrutinib in terms of response rate, PFS and OS, with a $57 \%$ reduction in the rate of death versus ofatumumab. ${ }^{[54]}$ Based on these results, ibrutinib was FDA-approved for CLL patients who have received at least one prior therapy, as well as for all Del(17p) CLL patients, considered to have the poorest prognosis. Three-year follow-up data of ibrutinib in CLL showed acceptable toxicity and continued activity with sustained responses that improve in quality over time. ${ }^{[55]}$ Recently, results from RESONATE-2, the phase 3 study of ibrutinib versus chlorambucil, in patients 65 years or older with treatmentnaive CLL/SLL, showed increased overall response rate and improved overall survival with ibrutinib. ${ }^{[56]}$ Ibrutinib was thus deemed superior to chlorambucil in previously untreated patients over 65 years old with CLL/SLL, setting the ground for the incorporation of ibrutinib in first-line treatment of CLL. Nevertheless, more data are needed, as chlorambucil is seldom used alone in clinical practice; it is usually combined with rituximab (anti-CD20 mAb) and fludarabine - a purine analogue - if the patient is fit and negative for $\operatorname{Del}(17 p)[\operatorname{Del}(17 p)$ confers resistance to standard chemotherapy]. What is more, cyclophosphamide, another alkylating agent, is often preferred over chlorambucil, again, in combination with fludarabine and rituximab (FCR regimen). Thus, as far as the first-line treatment is concerned, it still remains to be seen whether ibrutinib is as good as FCR or if, perhaps, a combination of ibrutinib and rituximab can improve the outcome and prognosis compared to FCR.

Ibrutinib was also FDA-approved for patients with $\mathrm{MCL}$, who have received at least one previous therapy, based on the results of a phase 2 study in relapsed or refractory $\mathrm{MCL}$ that showed a $68 \%$ response rate ${ }^{[57]}$ and median OS of 22.5 months after an extended 2-year follow-up period. ${ }^{[58]}$ Ibrutinib combinations with other drugs, such as rituximab, are also under study in a similar setting. ${ }^{[59]}$

Finally, following a study of ibrutinib in previously treated patients with WM that showed sustained responses and limited toxicity, ${ }^{[60]}$ the drug was also FDA-approved as a second-line treatment for WM patients or even first-line for those unsuitable for chemoimmunotherapy. The responses achieved with ibrutinib in patients with $A B C$ DLBCL were good, ${ }^{[61]}$ but the drug has not been approved for use in those patients yet.

Finally, novel Btk inhibitors, more selective and more potent than ibrutinib, are under clinical studies, promising more therapeutic choices for B-cell lymphomas.[62]

\section{Conclusion}

Btk is a non-receptor protein kinase involved in BCR signalling, necessary not only for antigen-specific humoral immunity, but also cell survival and maturation. As it is linked to various B-cell malignancies, including CLL, MCL and WM, it represents a prime therapeutic target in their treatment. Ibrutinib, a selective Btk inhibitor, has already been shown effective in selected patients with CLL, MCL and WM, but it is currently being tested for the treatment of other B-cell malignancies as well. Recent results from RESONATE-2, the phase 3 study of ibrutinib versus chlorambucil in patients 65 years or older with treatment-naive CLL/SLL, favoured ibrutinib over chlorambucil, laying the groundwork for the incorporation of ibrutinib in the first-line treatment of CLL patients. Ibrutinib has already improved CLL therapeutics, in the sense that it constitutes an effective, well-tolerated alternative for patients refractory to classic treatment, and it might advance it even further, perhaps as part of a new combination regimen, as more and more data are gathered.

\section{Conflict of Interest}

The authors declare that there is no conflict of interest. 
[1] Vetrie D, Vorechovsky I, Sideras P, Holland J, Davies A, Flinter $F$ et al. The gene involved in $\mathrm{X}$-linked agammaglobulinaemia is a member of the src family of protein-tyrosine kinases. Nature. 1993;361:226-233.

[2] Tsukada S, Saffran DC, Rawlings DJ, Parolini O, Allen RC, Klisak I et al. Deficient expression of a B cell cytoplasmic tyrosine kinase in human X-linked agammaglobulinemia. Cell 1993;72:279-290.

[3] Thomas DJ, Sideras P, Smith Cl, Vorechovsky I, Chapman V, Paul WE. Colocalization of $X$-linked agammaglobulinemia and X-linked immunodeficiency genes. Science. 1993;261:355-8.

[4] Rawlings DJ, Saffran DC, Tsukada S, Largaespada DA, Grimaldi JC, Cohen L et al. Mutation of unique region ofBruton's tyrosine kinase in immunodeficient XID mice. Science. 1993;261:358-61.

[5] Khan WN. Regulation of B lymphocyte development and activation by Bruton's tyrosine kinase. Immunol Res. 2001;23(2-3):147-56.

[6] Fruman DA, Satterthwaite AB, Witte ON. Xid-like phenotypes: a B cell signalosome takes shape. Immunity. 2000;13(1):1-3.

[7] Smith Cl, Baskin B, Humire-Greiff P, Zhou JN, Olsson PG, Maniar HS et al. Expression of Bruton's agammaglobulinemia tyrosine kinase gene, BTK, is selectively down-regulated in T lymphocytes and plasma cells. J Immunol. 1994;152:557-565.

[8] Mohamed AJ, Yu L, Bäckesjö CM, Vargas L, Faryal R, Aints A et al. Bruton's tyrosine kinase (Btk): function, regulation, and transformation with special emphasis on the PH domain. Immunol Rev. 2009;228(1):58-73.

[9] Mohamed AJ, Nore BF, Christensson B, Smith Cl. Signalling of Bruton's tyrosine kinase, Btk. Scand J Immunol. 1999;49(2):113-8.

[10] Niiro H, Clark EA. Regulation of B-cell fate by antigen-receptor signals. Nat Rev Immunol. 2002;2(12):945-56.

[11] Gauld SB, Dal Porto JM, Cambier JC. B cell antigen receptor signaling: roles in cell development and disease. Science. 2002;296(5573):1641-2.

[12] Kurosaki T, Takata M, Yamanashi Y, Inazu T, Taniguchi T, Yamamoto $\mathrm{T}$ et al. Syk activation by the Src-family tyrosine kinase in the B cell receptor signaling. J Exp Med. 1994;179(5):1725-9.

[13] Kurosaki T, Johnson SA, Pao L, Sada K, Yamamura $\mathrm{H}$, Cambier JC. Role of the Syk autophosphorylation site and $\mathrm{SH} 2$ domains in $\mathrm{B}$ cell antigen receptor signaling. J Exp Med. 1995;182(6):1815-23.
[14] Varnai P, Rother KI, Balla T. Phosphatidylinositol 3-kinase-dependentmembrane association of the Bruton's tyrosine kinase pleckstrin homology domain visualized in single living cells. J Biol Chem 1999;274(16):10983-10989.

[15] Yang W, Desiderio S. BAP-135, a target for Bruton's tyrosine kinase in response to $B$ cell receptor engagement. Proc Natl Acad Sci U S A. 1997;94(2):604-609.

[16] Park H, Wahl MI, Afar DE, Turck CW, Rawlings DJ, Tam C et al. Regulation of Btk function by a major autophosphorylation site within the SH3 domain. Immunity. 1996;4(5):515-525.

[17] Rodriguez R, Matsuda M, Perisic O, Bravo J, Paul A, Jones NP et al. Tyrosine residues in phospholipase Cgamma2 essential for the enzyme function in B-cell signaling. J BiolChem. 2001;276(51):4798247992.

[18] Humphries LA, Dangelmaier C, Sommer K, Kipp K, Kato RM, Griffith N et al. Tec kinases mediate sustained calcium influx via site-specific tyrosine phosphorylation of the phospholipase Cgamma Src homology 2-Src homology 3 linker. J Biol Chem. 2004;279(36):37651-61.

[19] Liu JL, Chiles TC, Sen RJ, Rothstein TL. Inducible nuclear expression of NF-kappa B in primary B cells stimulated through the surface Ig receptor. J Immunol. 1991;146(5):1685-91.

[20] Saito K, Tolias KF, Saci A, Koon HB, Humphries LA, Scharenberg A et al. BTK regulates Ptdlns-4,5-P2 synthesis: importance for calcium signaling and PI3K activity. Immunity. 2003;19(5):669-78.

[21] de Gorter DJ, Beuling EA, Kersseboom R, Middendorp S, van Gils JM, Hendriks RW et al. Bruton's tyrosine kinase and phospholipase Cgamma2 mediate chemokine-controlled B cell migration and homing. Immunity. 2007;26:93-104.

[22] Ortolano S, Hwang IY, Han SB, Kehrl JH. Roles for phosphoinositide 3-kinases, Bruton's tyrosine kinase, and Jun kinases in B lymphocyte chemotaxis and homing. Eur J Immunol. 2006;36:1285-1295.

[23] Ghia P, Chiorazzi N, Stamatopoulos K. Microenvironmental influences in chronic lymphocytic leukaemia: the role of antigen stimulation. J Intern Med. 2008;264(6):549-62.

[24] Burger JA. Nurture versus nature: the microenvironment in chronic lymphocytic leukemia. Hematology Am Soc Hematol Educ Program. 2011;2011:96-103.

[25] Fais F, Ghiotto F, Hashimoto S, Sellars B, Valetto A, Allen SL et al. Chronic lymphocytic leukemia B cells 
express restricted sets of mutated and unmutated antigen receptors. J Clin Invest. 1998;102:151525.

[26] Chiorazzi N, Ferrarini M. B cell chronic lymphocytic leukemia: lessons learned from studies of the $B$ cell antigen receptor. Annu Rev Immunol. 2003;21:84194.

[27] Murray F, Darzentas N, Hadzidimitriou A, Tobin G, Boudjogra M, Scielzo $C$ et al. Stereotyped patterns of somatic hypermutation in subsets of patients with chronic lymphocytic leukemia: implications for the role of antigen selection in leukemogenesis. Blood. 2008;111(3):1524-1533.

[28] Tobin G, Thunberg U, Johnson A, Eriksson I, Soderberg $\mathrm{O}$, Karlsson $\mathrm{K}$ et al. Chronic lymphocytic leukemias utilizing the $\mathrm{VH} 3-21$ gene display highly restricted Vlambda2-14 gene use and homologous CDR3s: implicating recognition of a common antigen epitope. Blood. 2003;101:4952-7.

[29] Widhopf GF 2nd, Rassenti LZ, Toy TL, Gribben JG, Wierda WG, Kipps TJ. Chronic Iymphocytic leukemia $B$ cells of more than $1 \%$ of patients express virtually identical immunoglobulins. Blood. 2004;104:2499-504.

[30] Messmer BT, Albesiano E, Efremov DG, Ghiotto F, Allen SL, Kolitz $J$ et al. Multiple distinct sets of stereotyped antigen receptors indicate a role for antigen in promoting chronic lymphocytic leukemia. J Exp Med. 2004;200:519-25.

[31] Tobin G, Thunberg U, Karlsson K, Murray $F$, Laurell A, Willander $K$ et al. Subsets with restricted immunoglobulin gene rearrangement features indicate a role for antigen selection in the development of chronic lymphocytic leukemia. Blood. 2004;104:2879-85.

[32] Potter KN, Orchard J, Critchley E, Mockridge $\mathrm{Cl}$, Jose A, Stevenson FK. Features of the overexpressed V1-69 genes in the unmutated subset of chronic lymphocytic leukemia are distinct from those in the healthy elderly repertoire. Blood. 2003;101:3082-4.

[33] Widhopf GF 2nd, Kipps TJ. Normal B cells express $51 \mathrm{p} 1$-encoded Ig heavy chains that are distinct from those expressed by chronic lymphocytic leukemia B cells. J Immunol. 2001;166: 95-102.

[34] Stevenson FK, Caligaris-Cappio F. Chronic lymphocytic leukemia: revelations from the B-cell receptor. Blood. 2004;103(12):4389-95.

[35] Chiorazzi N, Rai KR, Ferrarini M. Chroniclymphocytic leukemia. N Engl J Med. 2005;352(8):804-15.

[36] Darzentas N, Hadzidimitriou A, Murray F, Hatzi $\mathrm{K}$, Josefsson $\mathrm{P}$, Laoutaris $\mathrm{N}$ et al. A different ontogenesis for chronic lymphocytic leukemia cases carrying stereotyped antigen receptors: molecular and computational evidence. Leukemia. 2010;24(1):125-132.

[37] Mockridge CI, Potter KN, Wheatley I, Neville LA, Packham G, Stevenson FK. Reversible anergy of slgM-mediated signaling in the two subsets of CLL defined by $\mathrm{VH}$-gene mutational status. Blood. 2007;109(10):4424-31.

[38] Stevenson FK, Krysov S, Davies AJ, Steele AJ, Packham G. B-cell receptor signaling in chronic lymphocytic leukemia. Blood. 2011;118(16):431320.

[39] Swerdlow SH, Campo E, Harris NL, Jaffe ES, Pileri SA, Stein Harald et al. WHO Classification of Tumours of Haematopoietic and Lymphoid Tissues. IARC Press: Lyon 2008;2:180-2.

[40] Hadzidimitriou A, Agathangelidis A, Darzentas N, Murray F, Delfau-Larue $\mathrm{MH}$, Pedersen LB et al. Is there a role for antigen selection in mantle cell lymphoma? Immunogenetic support from a series of 807 cases. Blood. 2011;118(11):3088-95.

[41] Pérez-Galán $P$, Dreyling $M$, Wiestner A. Mantle cell lymphoma: biology, pathogenesis, and the molecular basis of treatment in the genomic era. Blood. 2011;117(1):26-38.

[42] Davis RE, Ngo VN, Lenz G, Tolar P, Young RM, Romesser PB et al. Chronic active B-cell-receptor signalling in diffuse large B-cell lymphoma. Nature. 2010;463(7277):88-92.

[43] Advani RH, Buggy JJ, Sharman JP, Smith SM, Boyd TE, Grant B et al. Bruton tyrosine kinase inhibitor ibrutinib (PCl-32765) has significant activity in patients with relapsed/refractory B-cell malignancies. J Clin Oncol. 2013;31(1):88-94.

[44] Yang G, Zhou Y, Liu X, Xu L, Cao Y, Manning RJ et al. A mutation in MYD88 (L265P) supports the survival of lymphoplasmacytic cells by activation of Bruton tyrosine kinase in Waldenström macroglobulinemia. Blood. 2013;122(7):1222-32.

[45] Fernandez-Vega I, Quiros LM, Santos-Juanes J, Pane-Foix M, Marafioti T. Bruton's tyrosine kinase (Btk) is a useful marker for Hodgkin and B cell nonHodgkin lymphoma. Virchows Arch. 2015;466:229235.

[46] Hamadani M, Balasubramanian S, Hari PN. Ibrutinib in Refractory Classic Hodgkin's Lymphoma. N Engl J Med. 2015;373(14):1381-2.

[47] Akinleye A, Avvaru P, Furqan M, Song Y, Liu D. Phosphatidylinositol 3-kinase (PI3K) inhibitors as cancer therapeutics. J Hematol Oncol. 2013;6(1):88.

[48] ten Hacken E, Burger JA. Molecular pathways: targeting the microenvironment in chronic 
lymphocytic leukemia--focus on the B-cell receptor. Clin Cancer Res. 2014;20(3):548-56.

[49] Honigberg LA, Smith AM, Sirisawad M, Verner E, Loury D, Chang B et al. The Bruton tyrosine kinase inhibitor $\mathrm{PCl}-32765$ blocks B-cell activation and is efficacious in models of autoimmune disease and B-cell malignancy. Proc Natl Acad Sci U S A. 2010;107(29):13075-13080.

[50] Herman SE, Gordon AL, Hertlein E, Ramanunni A, Zhang $X$, Jaglowski $S$ et al. Bruton tyrosine kinase represents a promising therapeutic target for treatment of chronic lymphocytic leukemia and is effectively targeted by PCl-32765. Blood. 2011;117(23):6287-96.

[51] Ponader S, Chen SS, Buggy JJ, Balakrishnan K, Gandhi V, Wierda WG et al. The Bruton tyrosine kinase inhibitor $\mathrm{PCl}-32765$ thwarts chronic lymphocytic leukemia cell survival and tissue homing in vitro and in vivo. Blood. 2012;119(5):1182-9.

[52] Byrd JC, Furman RR, Coutre SE, Flinn IW, Burger JA, Blum KA et al. Targeting BTK with ibrutinib in relapsed chronic lymphocytic leukemia. $\mathrm{N}$ Engl J Med. 2013;369(1):32-42.

[53] O'Brien S, Furman RR, Coutre SE, Sharman JP, Burger JA, Blum KA et al. Ibrutinib as initial therapy for elderly patients with chronic lymphocytic leukaemia or small lymphocytic lymphoma: an open-label, multicentre, phase $1 \mathrm{~b} / 2$ trial. Lancet Oncol. 2014;15(1):48-58.

[54] Byrd JC, Brown JR, O’Brien S, Barrientos JC, Kay NE, Reddy NM et al; RESONATE Investigators. Ibrutinib versus ofatumumab in previously treated chronic lymphoid leukemia. $N$ Engl J Med. 2014;371(3):213-23.

[55] Byrd JC, Furman RR, Coutre SE, Burger JA, Blum KA, Coleman $M$ et al. Three-year follow-up of treatment-naïve and previously treated patients with CLL and SLL receiving single-agent ibrutinib. Blood. 2015;125(16):2497-506.
[56] Burger JA, Tedeschi A, Barr PM, Tadeusz R, Owen C, Ghia P et al. RESONATE-2 Investigators. Ibrutinib as Initial Therapy for Patients with Chronic Lymphocytic Leukemia. N Engl J Med. 2015;373(25):2425-37.

[57] Wang ML, Rule S, Martin P, Goy A, Auer R, Kahl BS et al. Targeting BTK with ibrutinib in relapsed or refractory mantle-cell lymphoma. N Engl J Med. 2013;369(6):507-16.

[58] Wang M, Rule S, Martin P, Goy A, Auer R, Kahl B et al. (2014b) Single-agent ibrutinib demonstrates safety and durability of response at 2 years followup in patients with relapsed or refractory mantle cell lymphoma: updated results of an international, multicenter, open-label phase 2 study. Blood. (ASH Annual Meeting Abstracts) abstract 4453.

[59] Stephens DM, Spurgeon SE. Ibrutinib in mantle cell lymphoma patients: glass half full? Evidence and opinion. Ther Adv Hematol. 2015;6(5):242-52.

[60] Treon SP, Tripsas CK, Meid K, Warren D, Varma $G$, Green $R$ et al. Ibrutinib in previously treated Waldenström's macroglobulinemia. N Engl J Med. 2015;372(15):1430-40.

[61] Wilson WH, Young RM, Schmitz R, Yang Y, Pittaluga $S$, Wright $G$ et al. Targeting $B$ cell receptor signaling with ibrutinib in diffuse large B cell lymphoma. Nat Med. 2015;21(8):922-6.

[62] Wu J, Zhang M, Liu D. Acalabrutinib (ACP-196): a selective second-generation BTK inhibitor. J Hematol Oncol. 2016;9:21. 